\title{
Urosepsis Due to Extended-Spectrum B-Lactamase-Producing Escherichia coli: A Retrospective, Single-Centre Review of Risk Factors and Clinical Outcomes
}

\author{
Yi-Wenn Yvonne Huang, Alison Alleyne, Vivian Leung, and Michael Chapman
}

\begin{abstract}
Background: Extended-spectrum B-lactamase (ESBL)-producing Enterobacteriaceae are pathogens that are implicated in urosepsis and may be associated with greater morbidity and mortality than non-ESBL Enterobacteriaceae. Identification of risk factors for ESBL infection may facilitate the selection of appropriate empiric therapy.

Objectives: The primary objectives were to determine the cumulative incidence of ESBL urosepsis, to identify major risk factors for ESBL urosepsis, and to determine the impact of international travel on development of ESBL urosepsis in an ethnically diverse Canadian population. The secondary objective was to characterize the outcomes of patients with ESBL urosepsis.
\end{abstract}

Methods: A single-centre retrospective nested case-control study was conducted from January 2011 to June 2013. The study cohort consisted of adult patients with urosepsis and positive results on blood culture for ESBL-producing and non-ESBL-producing Enterobacteriaceae. Multivariate analysis was then used to determine risk factors for ESBL urosepsis.

Results: The cumulative incidence of ESBL urosepsis at the study site was $19.4 \%$ (58/299) over 2.5 years. The 58 cases of ESBL urosepsis were compared with 118 controls (patients with urosepsis caused by non-ESBL Enterobacteriaceae). Significant predictors of ESBL urosepsis were chronic renal insufficiency (odds ratio [OR] 4.66, 95\% confidence interval [CI] $1.96-11.08 ; p<0.001)$ and travel to an endemic region in the previous 6 months (OR 4.62, 95\% CI 1.17-18.19; $p=0.029$ ), as well as Punjabi or Hindi as the primary language (OR 3.25, 95\% CI 1.45-7.29; $p=0.004)$ and male sex (OR 2.65, 95\% CI 1.21-5.80; $p=0.015$ ). Patients with ESBL urosepsis had worse prognosis - in terms of death or discharge with palliative measures only-than those with non-ESBL urosepsis (7/58 [12.1\%] versus 4/118 [3.4\%]; $p=0.042)$.

Conclusions: Institution-specific data support prompt recognition of patients at risk for ESBL infections. Chronic renal insufficiency, recent travel to regions endemic for ESBL-producing organisms, primary language of Punjabi or Hindi, and male sex were the strongest risk factors for ESBL urosepsis at the study centre. However, findings from this single-centre study may not be generalizable to other institutions.

\section{RÉSUMÉ}

Contexte : Les entérobactériacées productrices de ß-lactamases à spectre étendu (BLSE) sont des pathogènes en cause dans les cas d'urosepsie et peuvent être associées à des taux de morbidité et de mortalité supérieurs à ceux liés aux entérobactériacées ne produisant pas de BLSE. Lidentification des facteurs de risque pour l'infection à BLSE pourrait faciliter le choix d'une antibiothérapie empirique appropriée.

Objectifs : Les objectifs principaux étaient de déterminer l'incidence cumulative des cas d'urosepsie à BLSE, d'identifier les facteurs de risque importants d'urosepsie à BLSE et de découvrir les effets des voyages à l'étranger sur l'apparition d'urosepsie à BLSE dans une population multiethnique canadienne. L'objectif secondaire était d'offrir un portrait de l'issue des patients atteints d'urosepsie à BLSE.

Méthodes : Une étude cas-témoins emboîtée rétrospective a été menée dans un seul centre entre janvier 2011 et juin 2013. La cohorte était composée de patients adultes atteints d'urosepsie dont les résultats d'hémoculture étaient positifs pour des entérobactériacées produisant des BLSE ou pour des entérobactériacées ne produisant pas de BLSE. Une analyse multivariée a ensuite été utilisée afin de discerner les facteurs de risque pour l'urosepsie à BLSE.

Résultats : L'incidence cumulative des cas d'urosepsie à BLSE dans l'établissement à l'étude était de 19,4\% (58/299) sur 2,5 ans. Les 58 cas d'urosepsie à BLSE ont été comparés à 118 témoins (des patients atteints d'urosepsie causée par des entérobactériacées ne produisant pas de BLSE). Les meilleures variables explicatives d'urosepsie à BLSE étaient : l'insuffisance rénale chronique (risque relatif approché [RRA] de 4,66, intervalle de confiance [IC] à $95 \%$ de $1,96-11,08 ; p<0,001)$ et les voyages dans une région endémique au cours des six derniers mois (RRA de 4,62, IC à $95 \%$ de $1,17-18,19 ; p=0,029)$ ainsi que le punjabi ou l'hindi comme langue principale (RRA de 3,25, IC à $95 \%$ de 1,45-7,29; $p=0,004$ ) et le sexe masculin (RRA de 2,65, IC à $95 \%$ de $1,21-5,80$; $p=0,015)$. Les patients atteints d'urosepsie à BLSE présentaient un pronostic plus sombre - en ce qui touche le décès ou le congé avec pour seule prescription des mesures palliatives - que ceux atteints d'urosepsie causée par des entérobactériacées non productrices de BLSE (7/58 $[12,1 \%]$ contre $4 / 118$ [3,4\%], $p=0,042)$.

Conclusions : Des données propres à l'établissement incitent à dépister 
Keywords: extended-spectrum ß-lactamase urosepsis, risk factors, travel

Can J Hosp Pharm. 2018;71(2):119-27 rapidement les patients à risque d'infection à BLSE. L'insuffisance rénale chronique, les voyages récents dans des régions où les organismes producteurs de BLSE sont endémiques, le punjabi ou l'hindi comme langue principale et le sexe masculin représentaient les facteurs de risques les plus importants pour l'urosepsie à BLSE au centre à l'étude. Cependant, il se pourrait que les résultats provenant de la présente étude réalisée dans un seul centre ne puissent pas être généralisés à d'autres établissements.

Mots clés : urosepsie à ß-lactamases à spectre étendu, facteurs de risque, voyage

\section{INTRODUCTION}

$\mathrm{I}_{\mathrm{n}}^{\mathrm{n}}$ clinical practice, one of the most common types of bacterial infection encountered is urinary tract infection (UTI). ${ }^{1}$ Although most UTIs are acquired in the community, they are also among the most common nosocomial infections. ${ }^{2}$ Among urinary isolates, the most commonly implicated pathogens are Escherichia coli and Klebsiella spp. ${ }^{3,4}$ Through plasmid-mediated mechanisms, some species of Enterobacteriaceae acquire the ability to produce extended-spectrum B-lactamases (ESBLs), enzymes that hydrolyze ß-lactam antibiotics. ${ }^{5}$ These plasmid adaptations confer multidrug resistance to an array of broad-spectrum ß-lactam antibiotics, including monobactams and third-generation cephalosporins (e.g., cefotaxime, ceftriaxone, ceftazidime), ${ }^{3}$ thus creating clinical challenges by limiting the options for appropriate drug therapy. Carbapenems have been regarded as the treatment of choice for infections with ESBL-producing organisms, but the emergence of carbapenem-resistant Enterobacteriaceae has necessitated more judicious use of antimicrobial therapies. ${ }^{6}$

Globally, the increasing prevalence of infections due to ESBL-producing organisms has become an emerging public health concern. High prevalence of such organisms has been documented in regions such as South America and Asia, with the highest rates being observed in India (where $>55 \%$ of Klebsiella pneumoniae and $60 \%$ of $E$. coli clinical isolates from all sources produce ESBLs). ${ }^{7-9}$ In Canadian hospitals, the prevalence of ESBLproducing $E$. coli and $K$. pneumoniae has been reported as about $4.9 \%$ and is on the rise.,10 The prevalence of ESBL-producing organisms in hospitals in the provinces of British Columbia and Alberta collectively has been documented at 7.6\%, the highest across the nation. ${ }^{3}$ Surrey Memorial Hospital is the second-largest hospital in British Columbia. It serves a multicultural population with a diverse history of travel activity worldwide. Among all isolates in the region served by this hospital, the prevalence of ESBL-producing organisms has been documented as $11 \%$ for E. coli and 5\% for K. pneumoniae. ${ }^{11}$ Prospective studies have suggested that international travel to destinations with higher prevalence of ESBL-producing organisms - such as the Indian subcontinent, Asia, and northern Africa-may be a risk factor for colonization and infection by ESBL-producing Enterobacteriaceae. ${ }^{912-15}$
The literature suggests that ESBL-producing strains of E. coli are an important cause of bloodstream infections from a urinary source. ${ }^{16}$ The term "urosepsis" has been used to describe these serious UTIs. Bloodstream infections secondary to ESBLproducing organisms have been associated with a 2- to 3-fold increase in mortality, higher rates of treatment failure, and delayed time to initiation of appropriate antimicrobial therapy relative to infections with non-ESBL-producing organisms. ${ }^{16-19}$ Numerous studies have attempted to elucidate risk factors for acquiring infections secondary to ESBL-producing organisms; these factors have included prior hospitalization, admission to the intensive care unit, recurrent UTIs, previous exposure to antibiotics (particularly oxyimino ß-lactams), previous invasive procedures of the urinary tract, and international travel. ${ }^{14,15,20-24}$ The primary objectives of the current study were to evaluate the cumulative incidence of ESBL urosepsis at Surrey Memorial Hospital and to identify major risk factors and the impact of international travel on development of active ESBL infections in an ethnically diverse Canadian population. The secondary objective was to characterize the outcomes of patients with ESBL urosepsis.

\section{METHODS}

\section{Study Population and Design}

This study was a chart review of electronic health records conducted at Surrey Memorial Hospital, a 650-bed community care hospital. The study included patients 19 years of age or older with a diagnosis of urosepsis between January 2011 and June 2013. Patients were initially identified by screening the electronic health records for positive results of blood culture for $E$. coli or $K$. pneumoniae, as obtained by testing with a VITEK 2 instrument (bioMérieux Vitek Systems Inc). The electronic health records of patients initially identified were further reviewed by study investigators to determine the presence of urosepsis. Patients were deemed to have had urosepsis if they had positive results on blood culture for $E$. coli or $K$. pneumoniae due to a urinary source and if they presented with 2 or more of the criteria for systemic inflammatory response syndrome, as follows: temperature above $38.5^{\circ} \mathrm{C}$ or below $36^{\circ} \mathrm{C}$, leukocyte count less than $4 \times 10^{9} / \mathrm{L}$ or greater than $12 \times 10^{9} / \mathrm{L}$, heart rate greater than 90 beats $/ \mathrm{min}$, and respiratory rate greater than 20 breaths/min. For patients with 
multiple episodes of urosepsis in the defined study period, only the first episode was included in the analysis.

The analysis began with determination of the cumulative incidence of ESBL urosepsis at the study site, from a cohort of patients with urosepsis due to E. coli or $K$. pneumoniae. Then, a case-control study nested within the cohort was conducted to estimate the magnitude of effect of risk factors for urosepsis caused by those ESBL-producing Enterobacteriaceae. Cases were matched $1: 2$ to controls based on infection with the same organism (i.e., E. coli or $K$. pneumoniae). For each case of ESBL urosepsis, 2 controls were randomly selected from the pool of patients with urosepsis due to non-ESBL-producing Enterobacteriaceae. Random selection of controls was accomplished with the list randomization function in Excel software (Microsoft Corp, Redmond, Washington). Administrative health care data of the patients were analyzed, including inpatient electronic health records and records from PharmaNet, the provincial registry of all outpatient prescription drugs dispensed in British Columbia. This study was approved by the Fraser Health Research and Ethics Board as a quality improvement project and was deemed appropriate for exemption from informed patient consent.

\section{Data Collection}

Patient characteristics for data collection were determined a priori on the basis of previous literature and site-specific observations. Demographic and clinical information, including age, sex, residence, primary language, travel history, and comorbidities, were collected. The following outcomes were also evaluated: length of hospital stay, duration of antimicrobial treatment, time to appropriate antibiotic therapy, and all-cause mortality among patients who died in hospital.

Patients with an admission diagnosis of urosepsis and no hospitalizations in the previous $48 \mathrm{~h}$ were defined as having a community-acquired infection. For the purpose of this study, "hospitalization" was defined as a visit to the emergency department or admission to hospital, but did not include residence in a long-term care facility or assisted living arrangements. Hospitalized patients with onset of symptoms more than $48 \mathrm{~h}$ after admission or within $48 \mathrm{~h}$ after discharge from any hospital were deemed to have a nosocomial infection.

Travel history within the past 6 months, as ascertained from all admitted patients at triage, was collected from the electronic health record. Travel to an endemic region was defined as travel to any region with a prevalence of ESBL-producing organisms above $30 \%$, such as the subcontinent of India, Southeast Asia, China, the Middle East, South America, and northern Africa. ${ }^{8,13}$ The Surrey Memorial Hospital is situated in a diverse and multicultural community. Although not previously studied as a risk factor, primary language was collected from triage information as a surrogate marker for potential familial contact with household travellers or visitors from abroad.
Vital signs at the time of triage were evaluated for patients who presented to the emergency department. For patients whose urosepsis developed during the hospital stay, vital signs at the time the treating physician ordered initial blood cultures were evaluated.

Chronic renal insufficiency was defined as estimated glomerular filtration rate (eGFR) less than $60 \mathrm{~mL} / \mathrm{min}$ per $1.73 \mathrm{~m}^{2}$ for a duration of 3 months or longer before the onset of infection. The eGFR was determined (as part of the current study) from the Modification of Diet in Renal Disease equation.

Appropriate antimicrobial therapy was defined as IV or oral agents to which the organism was susceptible. Use of $ß$-lactam and ß-lactamase inhibitors (e.g., piperacillin-tazobactam) as empiric therapy was considered inappropriate in cases of ESBL urosepsis. The time to appropriate antimicrobial therapy was calculated as the interval from time of sampling for initial blood cultures to time of receiving the first dose of antimicrobial therapy to which the organism was susceptible. Furthermore, patients were deemed to have received appropriate antimicrobial therapy within $24 \mathrm{~h}$ if the antibiotic was started within $24 \mathrm{~h}$ from the time of initial blood culture.

All-cause mortality was evaluated on the basis of in-hospital death. Patients who were discharged but whose care was withdrawn because of deteriorating clinical status (i.e., death was imminent) were deemed to be receiving palliative measures only.

\section{Statistical Analysis}

The distributions of the variables were examined using the Student $t$ test, the $\chi^{2}$ test, or the Fisher exact test, as deemed appropriate. Clinical outcomes were analyzed using the MannWhitney $U$ test. To estimate the strength of the association between each covariate and ESBL-related urosepsis, univariate regression analyses were performed, with a covariate as the only explanatory variable and ESBL-related urosepsis as the outcome variable. Then, a series of multivariate models were fitted iteratively, beginning with variables that were deemed clinically significant with a $p$ value less than 0.05 in the univariate analyses. At each step, one additional variable was entered into the model, and the model fit was assessed using the Hosmer-Lemeshow goodness-of-fit test and the corresponding $p$ value. The final model was fitted with only the strongest predictors of ESBLrelated urosepsis, as determined by the highest HosmerLemeshow $p$ value. Alternative model specifications were explored in multivariate analyses to determine the sensitivity of the results to other combinations of variables. The analyses were performed using the SPSS version 15.0 statistical software package (SPSS Inc, Chicago, Illinois).

\section{RESULTS}

The selection of patients for this study is outlined in Figure 1. The organisms of interest, E. coli and $K$. pneumoniae, were identified in blood cultures from 503 unique patients during the 


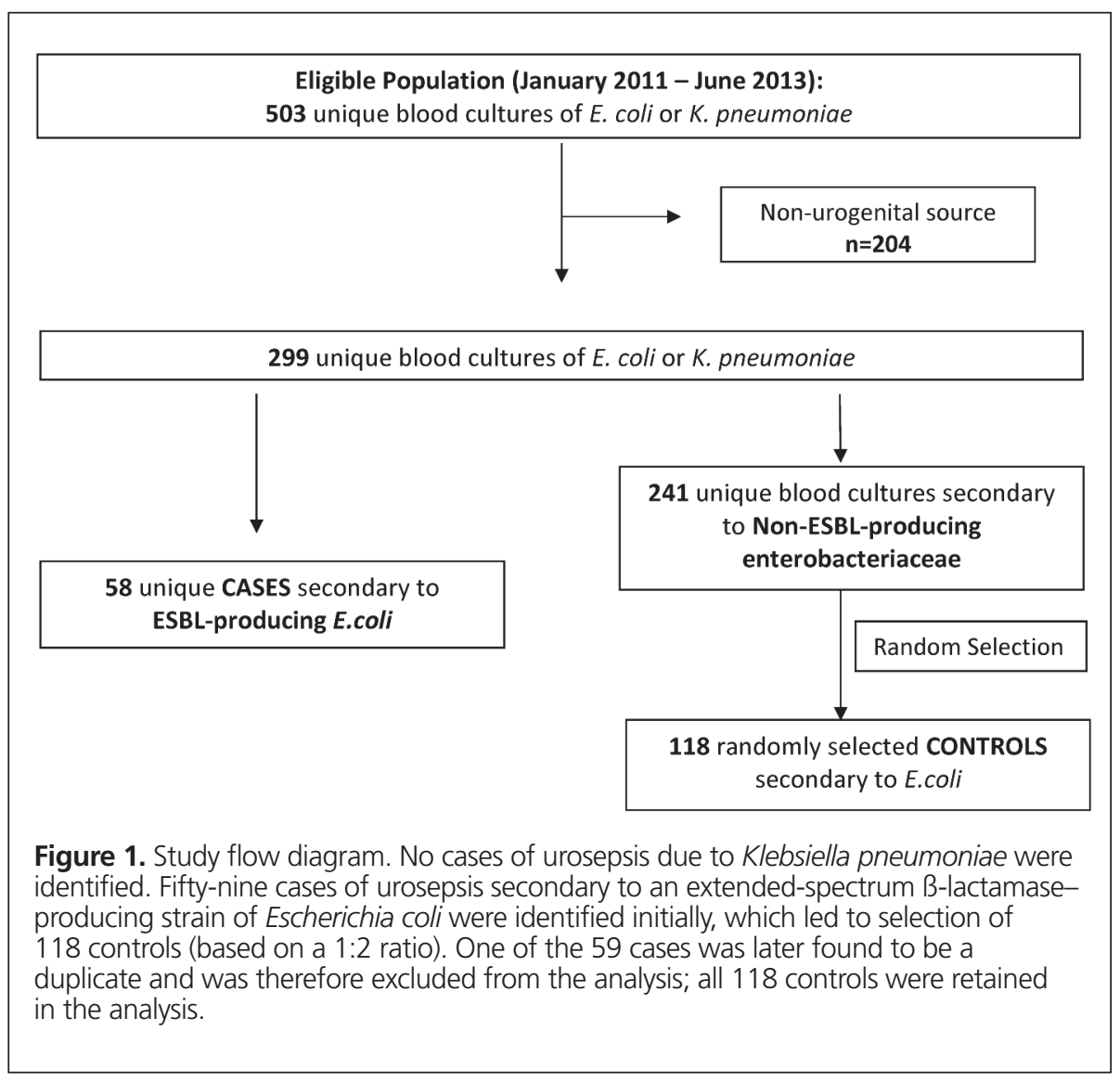

study period; of these, 299 unique patients (59.4\%) had urosepsis. We initially identified 59 cases of urosepsis secondary to an ESBLproducing strain of $E$. coli, but 1 case was later found to be a duplicate and was excluded from the analyses. The 58 cases resulted in a cumulative incidence of urosepsis due to ESBLproducing E. coli at this site of $19.4 \%$ (58/299) over the 2.5-year study period. No cases of ESBL $K$. pneumoniae urosepsis were identified. From the patients with non-ESBL-producing E. coli, the first 118 unique patients that met the inclusion criteria were selected as controls (based on initial identification of 59 cases and a 1:2 ratio of cases to controls); all 118 controls were retained for analysis. Therefore, a total of 176 patients were included in this case-control study.

\section{Patient Characteristics and Comorbidities}

Patient characteristics, including recent travel history and comorbidities, are shown in Table 1 . The mean age of all 176 patients was 67 years, and 72 (40.9\%) were men. There was no significant difference in age between case and control patients; however, a greater proportion of the case patients were men (33/58 [56.9\%] versus 39/118 [33.1\%]; $p=0.003)$. Most of the infections were acquired in the community (145/176 [82.4\%]). Univariate analysis suggested that primary language was a strong predictor of urosepsis secondary to an ESBL-producing organism, with case patients being more likely than control patients to speak Punjabi or Hindi as their primary language (33/58 [56.9\%] versus $26 / 118$ [22.0\%]; $p<0.001)$. Hospitalization in the previous 12 months was also more commonly seen among case patients than control patients (32/58 [55.2\%] versus 38/118 [32.2]; $p=0.005$ ). Travel history as a risk factor was evaluated, but was not found to be statistically significant. However, among the 20 patients with recent (past 6 months) travel to an endemic region, $12(60 \%)$ harboured an ESBL-producing organism. These 12 case patients with ESBL urosepsis and recent travel to an endemic region had all travelled to the subcontinent of India in the previous 6 months. Evaluation of comorbidities showed that case patients more frequently had renal insufficiency, recurrent UTIs, hepatitis $\mathrm{C}$ infection, tumour of the prostate or urinary tract, and benign prostatic hypertrophy. Univariate analysis showed that fluoroquinolone use in the previous 6 months was associated with acquisition of an ESBL-producing organism (24/58 [41.4\%] versus $24 / 118$ [20.3\%]; $p=0.004$ ), whereas no association was found with prior use of cephalosporins or penicillins (Table 2).

In the multivariate analysis (Table 3), the best-fit model demonstrated that the strongest predictors of urosepsis secondary to ESBL-producing organisms were chronic renal insufficiency (OR 4.66, 95\% CI 1.96-11.08; $p<0.001$ ) and travel to an endemic region in the previous 6 months (OR 4.62, 95\% 
Table 1. Patient Characteristics and Comorbidities

\begin{tabular}{|c|c|c|c|}
\hline \multirow[b]{2}{*}{ Characteristic } & \multicolumn{2}{|c|}{ Group; No. (\%) of Patients* } & \multirow[b]{2}{*}{$p$ Value } \\
\hline & $\begin{array}{l}\text { ESBL Urosepsis } \\
(n=58)\end{array}$ & $\begin{array}{c}\text { Non-ESBL } \\
\text { Urosepsis }(n=118)\end{array}$ & \\
\hline$\overline{\text { Age (years) }(\text { mean } \pm \text { SD) }}$ & $69.6 \pm 16.1$ & $66.2 \pm 18.7$ & 0.24 \\
\hline Sex, male & $33(56.9)$ & $39(33.1)$ & 0.003 \\
\hline Residence & & & 0.89 \\
\hline Home & $48(82.8)$ & $99(83.9)$ & \\
\hline Long-term care facility & $7(12.1)$ & $12(10.2)$ & \\
\hline Assisted living & $3 \quad(5.2)$ & $6 \quad(5.1)$ & \\
\hline Other & $0 \quad(0)$ & $1 \quad(0.8)$ & \\
\hline Primary language & & & $<0.001$ \\
\hline English & $19(32.8)$ & $75(63.6)$ & \\
\hline Punjabi or Hindi & $33(56.9)$ & $26(22.0)$ & \\
\hline Other & $1 \quad(1.7)$ & $7 \quad(5.9)$ & \\
\hline Unknown & $5 \quad(8.6)$ & $10 \quad(8.5)$ & \\
\hline \multicolumn{4}{|l|}{ Travel history } \\
\hline In past 6 months & $12(20.7)$ & $13(11.0)$ & 0.11 \\
\hline To endemic region in past 6 months & $12(20.7)$ & $8 \quad(6.8)$ & 0.010 \\
\hline \multicolumn{4}{|l|}{ Exposure } \\
\hline Community-acquired & $48(82.8)$ & $97(82.2)$ & $>0.99$ \\
\hline Nosocomial & $10(17.2)$ & $21(17.8)$ & $>0.99$ \\
\hline Hospitalization in past 12 months & $32(55.2)$ & $38(32.2)$ & 0.005 \\
\hline Sepsis at time of presentation & $45(77.6)$ & $82(69.5)$ & 0.29 \\
\hline $\begin{array}{l}\text { Urological procedurest within } \\
1 \text { month before admission }\end{array}$ & $10(17.2)$ & $14(11.9)$ & 0.36 \\
\hline \multicolumn{4}{|l|}{ Comorbidities } \\
\hline Diabetes mellitus & $27(46.6)$ & $42(35.6)$ & 0.19 \\
\hline CKD $\left(e G F R<60 \mathrm{~mL} /\right.$ min per $\left.1.73 \mathrm{~m}^{2}\right)$ & $27(46.6)$ & $18(15.3)$ & $<0.001$ \\
\hline Hemodialysis & $2(3.4)$ & $2(1.7)$ & 0.60 \\
\hline Recurrent UTI (> 3/year) & $22(37.9)$ & $19(16.1)$ & 0.002 \\
\hline Pregnancy & $3(5.2)$ & $5 \quad(4.2)$ & 0.72 \\
\hline Stroke or TIA & $14(24.1)$ & $17(14.4)$ & 0.14 \\
\hline Neurological disorder $\neq$ & $8(13.8)$ & $13(11.0)$ & 0.62 \\
\hline \multicolumn{4}{|l|}{ Immunocompromise } \\
\hline HIV & $(1.7)$ & (0) & $>0.99$ \\
\hline Hepatitis C & $(8.6)$ & $(1.7)$ & 0.040 \\
\hline Malignancy & $(6.9)$ & (8.5) & $>0.99$ \\
\hline Transplant recipient & $(0)$ & $(1.7)$ & $>0.99$ \\
\hline Use of immunosuppressants§ & $(5.2)$ & $(4.2)$ & 0.72 \\
\hline \multicolumn{4}{|l|}{ Urogenital comorbidities } \\
\hline Any structural malformation & $31(53.4)$ & $45(38.1)$ & 0.075 \\
\hline Urinary retention & $4 \quad(6.9)$ & 9 (7.6) & $>0.99$ \\
\hline Nephrolithiasis & $(6.9)$ & $13(11.0)$ & 0.59 \\
\hline Renal stents & $2 \quad(3.4)$ & $1(0.8)$ & 0.25 \\
\hline Tumour of prostate or urinary tract & $4 \quad(6.9)$ & $1 \quad(0.8)$ & 0.041 \\
\hline Benign prostatic hypertrophy & $14(24.1)$ & $13(11.0)$ & 0.028 \\
\hline Indwelling catheter & $8(13.8)$ & $14(11.9)$ & 0.81 \\
\hline
\end{tabular}

CKD = chronic kidney disease, eGFR = estimated glomerular filtration rate,

$\mathrm{ESBL}=$ extended-spectrum B-lactamase, SD = standard deviation, TIA = transient ischemic attack $\mathrm{UTI}=$ urinary tract infection

* Except where indicated otherwise.

†Transurethral prostate resection, insertion of renal stent, insertion of nephrostomy tube, biopsy of kidney and/or prostate, cystoscopy.

¥Spina bifida, multiple sclerosis, Alzheimer dementia, Parkinson disease, spinal cord injury. $\S$ Use of methotrexate, corticosteroids $>5 \mathrm{mg}$ equivalent of prednisone daily for $>14$ days, calcineurin inhibitors, chemotherapy, biologics, other immune modulators.

IUrinary retention, benign prostatic hypertrophy, indwelling catheter, malignancy of the prostate or urinary tract, renal stent, nephrolithiasis, urinary strictures, fistula, or trabeculation of the bladder. 
This single copy is for your personal, non-commercial use only.

For permission to reprint multiple copies or to order presentation-ready copies for distribution, contact CHHP at publications@cshp.ca

Table 2. Antibiotic Use during 6 Months before Admission

\begin{tabular}{lcccc} 
& \multicolumn{2}{c}{ Group; No. (\%) of Patients } & \\
\cline { 2 - 3 } Antibiotic Class* & $\begin{array}{c}\text { ESBL Urosepsis } \\
(\boldsymbol{n}=\mathbf{5 8})\end{array}$ & $\begin{array}{c}\text { Non-ESBL } \\
\text { Urosepsis }(\boldsymbol{n}=\mathbf{1 1 8})\end{array}$ & p Value \\
\hline Cephalosporins & $12(20.7)$ & $13(11.0)$ & 0.11 \\
Fluoroquinolones & $24(41.4)$ & $24(20.3)$ & 0.004 \\
B-Lactams & $19(32.8)$ & $24(20.3)$ & 0.09 \\
Any antibiotict & $36(62.1)$ & $40(33.9)$ & 0.001 \\
\hline
\end{tabular}

ESBL = extended-spectrum B-lactamase

* Patients received 1 or more doses of the antibiotic listed.

†Any systemic antibiotic received by patient (IV or oral), regardless of antibiotic class.

Table 3. Multivariate Regression Analysis

\begin{tabular}{lcccc} 
Variable & $\boldsymbol{B}$ & Standard Error & $\boldsymbol{p}$ value & OR $(\mathbf{9 5} \% \mathbf{C l})$ \\
\hline $\begin{array}{l}\text { Chronic renal insufficiency } \\
\left.\text { (eGFR }<60 \mathrm{~mL} / \text { min per 1.73 } \mathrm{m}^{2}\right)\end{array}$ & 1.539 & 0.442 & $<0.001$ & $4.66(1.96-11.08)$ \\
Travel to endemic region in & 1.530 & 0.699 & 0.029 & $4.62(1.17-18.19)$ \\
past 6 months & 1.178 & 0.412 & 0.004 & $3.25(1.45-7.29)$ \\
Primary language Punjabi or Hindi & 0.975 & 0.400 & 0.015 & $2.65(1.21-5.80)$ \\
\hline Male sex &
\end{tabular}

$\overline{\mathrm{Cl}}=$ confidence interval, eGFR = estimated glomerular filtration rate, $\mathrm{OR}=$ odds ratio.

CI $1.17-18.19 ; p=0.029)$. Speaking Punjabi or Hindi as the primary language (OR $3.25,95 \%$ CI $1.45-7.29 ; p=0.004)$ and male sex (OR 2.65, 95\% CI, 1.21-5.80; $p=0.015)$ were the next strongest predictive variables. The Hosmer-Lemeshow $p$ value was 0.961 , which suggested a well-fitted model. Of note, adjustment for age, hospitalization in the past 12 months, and previous antibiotic use did not significantly affect the clinical effect size of other variables or improve the fit of the model. Furthermore, the variables included in the final model were not collinear.

\section{Outcomes}

Among patients with urosepsis due to ESBL-producing organisms, the median length of hospital stay was 4 days longer (11 days versus 7 days; $p=0.003$ ) and treatment duration with antimicrobials was 1 day longer (14 days versus 13 days; $p=0.048)$ than for patients with urosepsis due to non-ESBLproducing organisms. Patients with ESBL-producing organisms less frequently received appropriate antimicrobial therapy within $24 \mathrm{~h}$ than control patients (48/58 [82.8\%] versus $112 / 118$ [94.9\%]; $p=0.012$ ). This finding also correlated with worse prognosis at discharge, with more patients experiencing all-cause mortality or being discharged with palliative measures only if they harboured an infection with an ESBL-producing organism. Outcomes are summarized in Table 4.

\section{DISCUSSION}

In this single-centre study, the cumulative incidence of urosepsis due to ESBL-producing E. coli over the 2.5-year study period was $19.4 \%$, higher than documented for other Canadian institutions. Studies from Winnipeg, Manitoba, have shown steady increases in the proportion of ESBL-producing E. coli in blood isolates, from $1.8 \%$ in 2008 to $10.3 \%$ in $2015 . .^{25}$ In a study from the Calgary Health Region, Peirano and others ${ }^{26}$ noted that $14 \%$ of E. coli blood isolates analyzed in 2010 were ESBLproducing organisms, primarily from a urinary source.

The current nested case-control study showed that, in decreasing order of significance, chronic renal insufficiency (eGFR $<60 \mathrm{~mL} / \mathrm{min}$ per $1.73 \mathrm{~m}^{2}$ ), travel to an endemic region in the past 6 months, primary language of Punjabi or Hindi (as a surrogate marker for familial transmission and contact abroad), and male sex were the strongest predictors of ESBL-related urosepsis. Although we had hypothesized that chronic renal insufficiency would be confounded by age, we found that age was not an influential variable in the presence of stronger predictors. Despite renal insufficiency being the strongest risk factor in the current study, there remains inconsistency in the literature with regard to this comorbidity as a risk factor for ESBL-related infections. ${ }^{7,21,22,27}$

The current literature suggests that international travelparticularly to the Indian subcontinent, Southeast Asia, and the Middle East - is a risk factor for fecal colonization and infection by multidrug-resistant organisms, including ESBL-producing bacteria. ${ }^{9}{ }^{12-15,28,29}$ In the COMBAT study, a large-scale longitudinal study, $34.3 \%$ of Dutch travellers returning from international travel had newly acquired colonization with ESBL-producing Enterobacteriaceae, and $11.3 \%$ of these individuals had persistent colonization at 12 months following return. ${ }^{24}$ The authors of the COMBAT study calculated that nontravelling household members had a $12 \%$ probability of colonization with ESBL-producing Enterobacteriaceae. ${ }^{24}$ Similar to previous studies, we found that international travel was associ- 
This single copy is for your personal, non-commercial use only.

For permission to reprint multiple copies or to order presentation-ready copies for distribution, contact CHHP at publications@cshp.ca

Table 4. Clinical Outcomes of Patients with ESBL or Non-ESBL Urosepsis

\begin{tabular}{|c|c|c|c|}
\hline \multirow[b]{2}{*}{ Outcome } & \multicolumn{2}{|c|}{$\begin{array}{c}\text { Group; Median (IQR) or } \\
\text { No. (\%) of Patients } \\
\end{array}$} & \multirow[b]{2}{*}{$p$ Value } \\
\hline & $\begin{array}{l}\text { ESBL Urosepsis } \\
\quad(n=58)\end{array}$ & $\begin{array}{c}\text { Non-ESBL } \\
\text { Urosepsis }(n=118)\end{array}$ & \\
\hline Duration of hospital admission (days) & $11(6-27)$ & $7(3-13)$ & 0.003 \\
\hline Total duration of treatment (days) & $14(9-28)$ & $13(9-17)$ & 0.048 \\
\hline $\begin{array}{l}\text { Received appropriate treatment } \\
\text { within } 24 \mathrm{~h}\end{array}$ & $48(82.8)$ & $112(94.9)$ & 0.012 \\
\hline Time to appropriate treatment (h) & $4(1.5-18)$ & $2.5(1-7.8)$ & 0.067 \\
\hline $\begin{array}{l}\text { All-cause mortality or palliative } \\
\text { measures only on discharge }\end{array}$ & $7(12.1)$ & $4(3.4)$ & 0.042 \\
\hline
\end{tabular}

ated with acquiring ESBL infections; notably, however, most of the clinical isolates in those previous studies were obtained from urine only. ${ }^{12,14,15}$ In such instances, positive results on urine culture may represent colonization rather than true infection. Because we exclusively evaluated blood isolates, this is the first study (to our knowledge) that attempts to quantify the strength of foreign travel as a risk factor for definitive ESBL-related infections in an ethnically diverse Canadian population.

The Canadian census indicates that about $30 \%$ of individuals in the study region primarily speak a migrant language (i.e., a language other than Canada's official languages of English, French, and Aboriginal languages). ${ }^{30}$ We examined language as a surrogate marker, hypothesizing that primarily speaking a migrant language might suggest previous residence abroad or contact with visitors from abroad, both of which could be a modality of familial transmission. However, the association between primary language and risk of ESBL-related infection requires further investigation and validation through prospective studies.

The presence of multidrug-resistant organisms is commonly associated with prior hospitalization and is often regarded as "nosocomial" infection. ${ }^{8,31}$ An international multicentre study suggested that among nonhospitalized patients, male sex, age 65 years or older, recent antibiotic use, recent hospital admission, and residence in a long-term care facility were independent risk factors for acquiring ESBL-producing organisms; however, for patients with no previous health care contact, these variables showed poor predictive value. ${ }^{32}$ Although the patients in the current study had been admitted to hospital, our findings do corroborate the literature. Approximately half of the patients with ESBL urosepsis had no prior hospital admissions, and $82.8 \%$ of the ESBL infections were likely acquired in the community. The latter result is consistent with previous literature suggesting the growing prominence of community-acquired ESBL infections. ${ }^{14,15,33}$ As a result, the distinction between community-acquired and nosocomial cases may be confounded by colonization and/or horizontal transmission in the general population.

The impact of ESBL infections on mortality remains controversial. Some studies have suggested that ESBL bloodstream infections have been associated with a 2- to 3 -fold increase in morbidity and mortality. ${ }^{17,19}$ One meta-analysis found that there is often a delay in prescribing effective antibiotics for patients with ESBL bacteremia, which has implications for mortality outcomes. ${ }^{18}$ Other studies have demonstrated conflicting mortality outcomes in the presence of inadequate initiation of empiric antimicrobials. ${ }^{34,35}$ Length of stay has been studied in previous matched case-control studies, which have shown no differences between ESBL and non-ESBL bloodstream infections. ${ }^{34,36}$ Although increases in all-cause mortality and length of stay were observed in our study, the lack of demographic matching and the lack of statistical adjustments limit our interpretation of these findings. All-cause mortality and discharge on palliative measures only were assessed as a composite outcome, because death was deemed imminent for all 3 patients in the ESBL urosepsis group with palliative measures only at discharge.

Delay to effective antimicrobial therapy for patients with ESBL bloodstream infections has been consistently documented in the literature. ${ }^{18,34,35}$ As predicted, patients in the current study who harboured an ESBL-producing organism less often received appropriate empiric therapy. However, the median time to receipt of antimicrobial therapy was not statistically different between case and control patients. Clinicians often tailor empiric antimicrobial selection on the basis of previous microbial colonization, but prior colonization with ESBL-producing organisms was not analyzed a priori in the current study. In a post hoc analysis, we found that 14 of the case patients had prior colonization with ESBL-producing organisms. Such prior colonization could have affected the selection of antimicrobials in favour of agents that empirically target ESBL organisms, which would have shortened the median time to receipt of appropriate antimicrobials in the ESBL urosepsis group. Future studies should consider prior colonization as a study variable.

\section{Limitations}

This study had several limitations. It was a single-centre study within a unique demographic region; therefore, the results may not be generalizable to other institutions. Moreover, our study primarily focused on E. coli urosepsis, and it may not be possible 
to extrapolate the risk factors identified here to other Enterobacteriaceae (e.g., Klebsiella spp., Proteus spp.). The small sample size may have limited the ability to detect a statistically significant difference among variables in the univariate analysis, which were then excluded from consideration in the multivariate regression analysis. Given the retrospective study design, there is the possibility of incomplete data for vital signs and symptoms, adherence history for antibiotics filled before admission, and past medical history. Moreover, without prospective follow-up, the accuracy of travel history as documented at triage may have been variable, which may have affected the accuracy of results. The COMBAT study demonstrated persistence of colonization for as long as 12 months after return from travel, ${ }^{24}$ whereas we assessed for travel only in the 6 months before admission; as such, it is possible that the risk of acquiring ESBL-producing Enterobacteriaceae was under-captured in our study. Primary language has not been previously documented or validated as a risk factor for acquisition of multidrug-resistant organisms. Given the retrospective nature of this study, we were unable to gather information on contact with visitors from abroad or household travel history. Furthermore, retention of migrant language is not always reflective of travel history or contact with visitors from abroad; therefore, no conclusions can be drawn regarding language as a surrogate risk factor.

\section{CONCLUSION}

Early identification of risk factors associated with ESBL urosepsis is important and may help clinicians to initiate appropriate empiric antimicrobial therapy. This study identified risk factors and quantified the impact of recent travel on the acquisition of ESBL-related urosepsis. Several outcomes were evaluated; however, larger-scale studies with statistical adjustments are required to validate these results. The findings in this singlecentre study highlight that sociodemographic risk factors may be just as clinically important as pre-existing comorbidities in the selection of empiric coverage. Institution-specific data support prompt recognition of patients at risk for ESBL infections, facilitate antimicrobial stewardship, and highlight the need to screen for and consider recent travel history when initiating empiric antibiotic therapy in patients presenting with urosepsis.

\section{References}

1. Foxman B. The epidemiology of urinary tract infection. Nat Rev Urol. 2010;7(12):653-60.

2. Gravel D, Taylor G, Ofner M, Johnston L, Loeb M, Roth VR, et al. Point prevalence survey of healthcare-associated infections within Canadian adult acute-care hospitals. J Hosp Infect. 2007;66(3):243-8.

3. Zhanel GG, DeCorby M, Adam H, Mulvey MR, McCraken M, LagacéWeins P, et al. Prevalence of antimicrobial-resistant pathogens in Canadian hospitals: results of the Canadian Ward Surveillance Study (CANWARD 2008). Antimicrob Agents Chemother. 2010;54(11):4684-93.

4. Hoban DJ, Nicolle LE, Hawser S, Bouchillon S, Badal R. Antimicrobial susceptibility of global inpatient urinary tract isolates of Escherichia coli: results from the Study for Monitoring Antimicrobial Resistance Trends
(SMART) program: 2009-2010. Diagn Microbiol Infect Dis. 2011;70(4): 507-11.

5. Jacoby GA, Medeiros AA. More extended-spectrum ß-lactamases. Antimicrob Agents. 1991;35(9):1697-704.

6. Vardakas KZ, Tansarli GS, Rafailidis PI, Falagas ME. Carbapenems versus alternative antibiotics for the treatment of bacteraemia due to Enterobacteriaceae producing extended-spectrum $ß$-lactamases: a systematic review and meta-analysis. J Antimicrob Chemother. 2012;67(12):2793-803.

7. Goyal A, Prasad KN, Prasad A, Gupta S, Ghoshal U, Ayyagari A. Extended spectrum B-lactamases in Escherichia coli and Klebsiella pneumoniae and associated risk factors. Indian J Med Res. 2009;129(6):695-700.

8. Hawser SP, Bouchillon SK, Hoban DJ, Badal RE, Hsueh PR, Paterson DL. Emergence of high levels of extended-spectrum- $B$-lactamase-producing gram-negative bacilli in the Asia-Pacific region: data from the Study for Monitoring Antimicrobial Resistance Trends (SMART) Program, 2007. Antimicrob Agents Chemother. 2009;53(8):3280-4.

9. Tängdén T, Cars O, Melhus A, Löwdin E. Foreign travel is a major risk factor for colonization with Escherichia coli producing CTX-M-Type extendedspectrum ß-lactamases: a prospective study with Swedish volunteers. Antimicrob Agents Chemother. 2010;54(9):3564-8.

10. Karlowsky JA, Lagacé-Wiens PRS, Simner PJ, DeCorby MR, Adam HJ, Walkty A, et al. Antimicrobial resistance in urinary tract pathogens in Canada from 2007 to 2009: CANWARD Surveillance Study. Antimicrob Agents Chemother. 2011;55(7):3169-75.

11. Fraser Health antibiograms: Fraser South antibiogram. Fraser Health; 2013 [cited 2017 Aug 18]. Available from: http://medicalstaff.fraserhealth.ca/ Clinical-Resources

12. Laupland KB, Church DL, Vidakovich J, Mucenski M, Pitout JDD. Community-onset extended-spectrum B-lactamase (ESBL) producing Escherichia coli: importance of international travel. J Infect. 2008;57(6):441-8.

13. Östholm-Balkhed Å,Tärnberg M, Nilsson M, Nilsson LE, Hanberger H, Hällgren A. Travel associated faecal colonization with ESBL-producing Enterobacteriaceae: incidence and risk factors. I Antimicrob Chemother. 2013;68(9):2144-53.

14. Strysko JP, Mony V, Cleveland J, Siddiqui H, Homel P, Gagliardo C. International travel is a risk factor for extended-spectrum ß-lactamaseproducing Enterobacteriaceae acquisition in children: a case-case-control study in an urban U.S. hospital. Travel Med Infect Dis. 2016;14(6):568-71.

15. Tham J, Odenholt I, Walder M, Andersson L, Melander E. Risk factors for infections with extended-spectrum beta-lactamase-producing Escherichia coli in a county of southern Sweden. Infect Drug Resist. 2013;6:93-7.

16. Tumbarello M, Sali M, Trecarichi EM, Leone F, Rossi M, Fiori B, et al. Bloodstream infections caused by extended-spectrum- $ß$-lactamase-producing Escherichia coli: risk factors for inadequate initial antimicrobial therapy. Antimicrob Agents Chemother. 2008;52(9):3244-52.

17. Tumbarello M, Sanguinetti M, Montuori E, Trecarichi EM, Posteraro B, Fiori B, et al. Predictors of mortality in patients with bloodstream infections caused by extended-spectrum-ß-lactamase-producing Enterobacteriaceae: importance of inadequate initial antimicrobial therapy. Antimicrob Agents Chemother. 2007;51(6):1987-94.

18. Schwaber MJ, Carmeli Y. Mortality and delay in effective therapy associated with extended-spectrum $B$-lactamase production in Enterobacteriaceae bacteremia: a systematic review and meta-analysis. J Antimicrob Chemother. 2007;60(5):913-20.

19. Melzer M, Petersen I. Mortality following bacteraemic infection caused by extended spectrum beta-lactamase (ESBL) producing E. coli compared to non-ESBL producing E. coli. J Infect. 2007;55(3):254-9.

20. Briongos-Figuero LS, Gómez-Traveso T, Bachiller-Luque P, González MD, Gómez-Nieto A, Palacios-Martín T, et al. Epidemiology, risk factors and comorbidity for urinary tract infections caused by extended-spectrum beta-lactamase (ESBL)-producing enterobacteria. Int J Clin Pract. 2012; 66(9):891-6. 
21. Lautenbach E, Patel JB, Bilker WB, Edelstein PH, Fishman NO. Extendedspectrum ß-lactamase-producing Escherichia coli and Klebsiella pneumoniae: risk factors for infection and impact of resistance on outcomes. Clin Infect Dis. 2001;32(8):1162-71.

22. Ferrández Quirante O, Grau Cerrato S, Luque Pardos S. Risk factors for bloodstream infections caused by extended-spectrum ß-lactamase-producing Escherichia coli and Klebsiella pneumoniae. Braz J Infect Dis. 2011;15(4):370-6.

23. Rodríguez-Baño J, Navarro MD, Romero L, Muniain MA, Perea EJ, PérezCano R, et al. Clinical and molecular epidemiology of extended-spectrum B-lactamase-producing Escherichia coli as a cause of nosocomial infection or colonization: implications for control. Clin Infect Dis. 2006;42(1):37-45.

24. Arcilla MS, van Hattem JM, Haverkate M, Bootsma MCJ, van Genderen PJJ, Goorhuis A, et al. Import and spread of extended-spectrum B-lactamaseproducing Enterobacteriaceae by international travellers (COMBAT study): a prospective, multicentre cohort study. Lancet Infect Dis. 2017;17(1):78-85.

25. Walkty A, Lagacé-Wiens P, Karlowsky J. Extended-spectrum beta-lactamase producing Escherichia coli: increasing incidence of a resistant pathogen. DSM Micro Notes. Winnipeg (MB): Diagnostic Services Manitoba; 2016 Mar [cited 2017 Aug 18]. Available from: http://dsmanitoba.ca/wpcontent/uploads/2016/04/MNMar2016.pdf

26. Peirano G, van der Bij AK, Gregson DB, Pitout JDD. Molecular epidemiology over an 11-year period (2000 to 2010) of extended-spectrum ß-lactamase-producing Escherichia coli causing bacteremia in a centralized Canadian region. J Clin Microbiol. 2012;50(2):294-9.

27. Ben-Ami R, Schwaber MJ, Navon-Venezia S, Schwartz D, Giladi M, Chmelnitsky I, et al. Influx of extended-spectrum B-lactamase-producing Enterobacteriaceae into the hospital. Clin Infect Dis. 2006;42(7):925-34.

28. Peirano G, Ahmed-Bentley J, Woodford N, Pitout JD. New Delhi MetalloB-lactamase from traveler returning to Canada. Emerg Infect Dis. 2011; 17(2):242-4.

29. Kuenzli E, Jaeger VK, Frei R, Neumayr A, DeCrom S, Haller S, et al. High colonization rates of extended-spectrum ß-lactamase (ESBL)-producing Escherichia coli in Swiss travellers to South Asia-a prospective observational multicentre cohort study looking at epidemiology, microbiology and risk factors. BMC Infect Dis. 2014;14:528.

30. Linguistic characteristics of Canadians. Ottawa (ON): Statistics Canada: [modified 2015 Dec 22; cited 2017 Aug 18]. Available from: http://www12. statcan.gc.ca/census-recensement/2011/as-sa/98-314-x/98-314-x2011001eng.cfm

31. García-Tello A, Gimbernat H, Redondo C, Arana DM, Cacho J, Angulo JC. Extended-spectrum beta-lactamases in urinary tract infections caused by Enterobacteria: understanding and guidelines for action. Actas Urol Esp. 2014;38(10):678-84.

32. Ben-Ami R, Rodríguez-Baño J, Arslan H, Pitout JD, Quentin C, Calbo ES, et al. A multinational survey of risk factors for infection with extendedspectrum ß-lactamase-producing Enterobacteriaceae in nonhospitalized patients. Clin Infect Dis. 2009;49(5):682-90.
33. Woerther PL, Burdet C, Chachaty E, Andremont A. Trends in human fecal carriage of extended-spectrum B-lactamases in the community: toward the globalization of CTX-M. Clin Microbiol Rev. 2013;26(4):744-58.

34. Denis B, Lafaurie M, Donay JL, Fontaine JP, Oksenhendler E, Raffoux E, et al. Prevalence, risk factors, and impact on clinical outcome of extendedspectrum beta-lactamase-producing Escherichia coli bacteremia: a five year study. Int J Infect Dis. 2015;39:1-6.

35. Nguyen ML, Toye B, Kanji S, Zvonar R. Risk factors for and outcomes of bacteremia caused by extended-spectrum ß-lactamase-producing Escherichia coli and Klebsiella species at a Canadian tertiary care hospital. Can J Hosp Pharm. 2015;68(2):136-43.

36. Leistner R, Bloch A, Sakellariou C, Gastmeier P, Schwab F. Costs and length of stay associated with extended-spectrum ß-lactamase production in cases of Escherichia coli bloodstream infection. J Glob Antimicrob Resist. 2014; 2(2):107-9.

Yi-Wenn Yvonne Huang, BSC(Pharm), ACPR, is with the Pharmacy Department, Surrey Memorial Hospital, Surrey, British Columbia.

Alison Alleyne, BScPhm, PharmD, is with the Pharmacy Department, Surrey Memorial Hospital, Surrey, British Columbia.

Vivian Leung, BSC(Pharm), ACPR, PharmD, PhD, is with the Fraser Health Antimicrobial Stewardship Program, Surrey Memorial Hospital, Surrey, British Columbia.

Michael Chapman, MD, FRCPC, is with the Infectious Diseases Division of the Department of Medicine, Surrey Memorial Hospital, Surrey, British Columbia.

Competing interests: None declared.

Address correspondence to:

Yi-Wenn Yvonne Huang

Surrey Memorial Hospital

1375096 Avenue

Surrey BC V3V $1 Z 2$

e-mail: Yvonne.huang@fraserhealth.ca

Funding: None received.

Acknowledgements: The authors would like to thank Dr Benjamin Mack for providing the microbiological data needed to conduct this study and to the team's research assistant, Carly Hoffman, for assistance with data collection. 